$$
\begin{aligned}
& \text { CONE-961193--1 } \\
& \text { NREL/CP- }-540-21614
\end{aligned}
$$

Reducing VMTs through Transit
Demand with GPS and Satellite Communications

RECEIVED

OCT 301996

OSTI
K.B. Wipke

Prepared for the IEEE Northcon/96

Technical Applications Conference, Seattle, Washington, Nov. 4-6, 1996

National Renewable Energy Laboratory 1617 Cole Boulevard Golden, Colorado 80401-3393

A national laboratory of the U.S. Department of Energy Managed by Midwest Research Institute for the U.S. Department of Energy under Contract No. DE-AC36-83CH10093

Prepared under Task No. WU6D0101

October 1996 
$\sin \sin \sin$

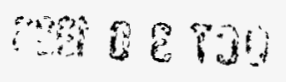

$? \cdots$

NOTICE

This report was prepared as an account of work sponsored by an agency of the United States government. Neither the United States government nor any agency thereof, nor any of their employees, makes any warranty, express or implied, or assumes any legal liability or responsibility for the accuracy, completeness, or usefulness of any information, apparatus, product, or process disclosed, or represents that its use would not infringe privately owned rights. Reference herein to any specific commercial product, process, or service by trade name, trademark, manufacturer, or otherwise does not necessarily constitute or imply its endorsement, recommendation, or favoring by the United States govemment or any agency thereof. The views and opinions of authors expressed herein do not necessarily state or reflect those of the United States government or any agency thereof.

Available to DOE and DOE contractors from:

Office of Scientific and Technical Information (OSTI)

P.O. Box 62

Oak Ridge, TN 37831

Prices available by calling (423) $576-8401$

Available to the public from:

National Technical information Service (NTIS)

U.S. Department of Commerce

5285 Port Royal Road

Springtield, VA 22161

(703) 487-4650 


\section{DISCLAIMER}

This report was prepared as an account of work sponsored by an agency of the United States Government. Neither the United States Government nor any agency thereof, nor any of their employees, makes any warranty, express or implied, or assumes any legal liability or responsibility for the accuracy, completeness, or usefulness of any information, apparatus, product, or process disclosed, or represents that its use would not infringe privately owned rights. Reference herein to any specific commercial product, process, or service by trade name, trademark, manufacturer, or otherwise does not necessarily constitute or imply its endorsement, recommendation, or favoring by the United States Government or any agency thereof. The views and opinions of authors expressed herein do not necessarily state or reflect those of the United States Government or any agency thereof. 


\section{DISCLAIMER}

Portions of this document may be illegible in electronic image products. Images are produced from the best available original document. 


\title{
Reducing VMTs Through Transit-On-Demand with GPS and Satellite Communications
}

\author{
Keith B. Wipke \\ National Renewable Energy Laboratory \\ 1617 Cole Blvd., Golden, CO 80401 \\ (303) 275-4451, keith_wipke@nrel.gov, http://www.tod.nrel.gov
}

\begin{abstract}
As a partial solution to the problem of increasing foreign petroleum imports, urban congestion, and air pollution from personal automobiles, researchers at the National Renewable Energy Laboratory in Golden, Colorado, have successfully demonstrated a transportation concept called Transit-On-Demand (TOD). TOD uses the global positioning system (GPS) to locate all vehicles in a fleet, two-way communications between the vehicles and a central computer-server, and advanced dispatching and routing software to control the movement of vehicles within the fleet. Reducing the vehicle-miles-travelled (VMTs) through implementing efficient transportation systems such as TOD, results in less energy being required for transportation and a decrease in the amount of required imported petroleum. Through development of an advanced world wide web site and use of the new Java ${ }^{\mathrm{TM}}$ Internet programming language, the demonstration allows visitors to the web site to see updates of vehicle position on a map every 20 seconds, while effectively minimizing the internet bandwidth required for this activity. The project demonstrates how a fixed-route, fixed-schedule shuttle can be converted to be demand-responsive to more effectively move people from where they are to where they want to be at the time they want to travel.
\end{abstract}

\section{Introduction}

The motivation for introducing a transportation option such as Transit-On-Demand is multi-faceted. From an energy perspective, the United States has an interest in decreasing energy usage in the transportation sector to cut down on imported petroleum. Since the projects discussed in this study are sponsored by the Department of Energy (DOE), this energy efficiency impact is the primary metric of the potential benefit for the TOD concept. Since getting people out of their cars and into multi-passenger vehicle trips both reduces energy usage and reduces vehicle miles traveled (VMT), the energy efficiency benefit can be rolled up into the goal of VMT reduction and referred to synonymously. When VMTs are reduced, there are also at least two other benefits gained: reduced traffic congestion and lower air pollution. It is for these last two reasons that urban transportation districts are looking for ways to get people out of their personal automobiles and into a vehicle carrying more than one passenger.

Although NREL has not typically been involved in intelligent transportation system (ITS) activities, the energy efficiency aspect of reducing VMTs warranted further exploration. The first phase of the project involved using NREL's fixed-route, fixed-schedule shuttle to demonstrate how a demand-responsive system could be implemented, and was more of a proof-of-concept project than a large scale demonstration. While this small-scale demonstration was in progress, preparations were made to begin a second phase of the project, involving the demonstration on a larger fleet of vehicles covering a larger area. This project is with the Jefferson County Seniors ${ }^{2}$ Resource Center in Colorado, and involves their fleet of 17 vehicles which shuttle elderly and handicapped people door-to-door.

\section{Goals of the NREL Shuttle Project}

The primary goal of the NREL TOD shuttle project was to convert the shuttle to be demand-responsive to the roughly 800 NREL staff and eliminate the fixed-route, fixed-schedule on which it was operating. In order to provide this demand-based dispatching without adding a human employee with voice communication to the driver, an innovative web site was created that allowed tracking of the shuttle vehicle and two-way digital communication with the driver. Because the focus of the demonstration was on the development of the software and demonstration of the concept, it was decided that bundled off-the-shelf hardware would be the most efficient means of accomplishing the goals of the project. Another goal of the project was to create an internet site to communicate the concepts of TOD to the rest of the world, provide information on technologies used in the demonstration, and create a set of resources for others wishing to explore the implementation of demand-based transportation.

This paper will discuss the concept of TOD in further detail and describe how the NREL shuttle project demonstrates most of these concepts. Explanation will be given on how Java ${ }^{\mathrm{TM}}$ programming was used in an innovative way to reduce the internet bandwidth 
requirement for updating vehicle positions on the web clients' maps. The difficulties encountered with the hardware and the software development will also be discussed, and details of other communications options besides the satellite-based system that was used during the NREL shuttle demonstration will be provided.

\section{The Concept of TOD}

\section{History of the TOD Concept}

In July of 1995, a consultant to NREL put together a draft proposal for a project to demonstrate that TOD technology works by performing an experiment with two vehicles at NREL. The information on the successes and failures of the demonstration would then be put on the world wide web for others to learn from. This project proposal was then approved through a program at NREL to help incubate such projects, and the project commenced in January 1996.

While progress was being made on the NREL shuttle demonstration, technology demonstrations to many other interested parties led to a second project supported by DOE's Transportation Demand Management (TDM) Program through DOE's Denver Regional Support Office. Details of this project will be discussed later, and the project is scheduled to begin at the conclusion of the NREL shuttle project in late September, 1996.

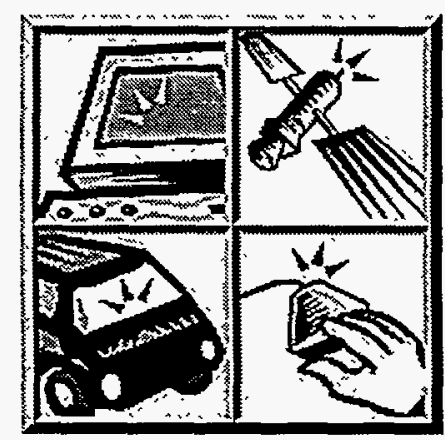

Figure 1: Transit-On-Demand Logo, Illustrating the Four Key Ingredients of the TOD Demonstration

\section{Fundamentals of TOD}

The implementation of the TOD concept is based on two very simple ideas. The first concept is knowing precisely where all vehicles in a shuttle fleet are at any given time through GPS and two-way electronic communication (which will be discussed in more detail later). The second fundamental concept of TOD is using advanced mapping software to take current vehicle locations, directions of travel, and passenger loading, combine it with incoming requests for rides, and use optimization routines in real-time to determine which vehicle should make the pickup and the optimal route for the vehicle to take. Figure 1 shows the TOD logo which illustrates four key ingredients of the NREL TOD demonstration: computing power for routing \& scheduling, two-way satellite communication, GPS on all vans which use the communication to talk to the computer server, and world wide web interactivity that allows ride requests and vehicle tracking to be just a mouse-click away. Figure 2 shows a picture of the mobile data terminal (MDT) with which the driver sends and receives messages. It should be noted that although this MDT may be rather large, a production fleet vehicle unit would most likely be smaller and integrated into the console.

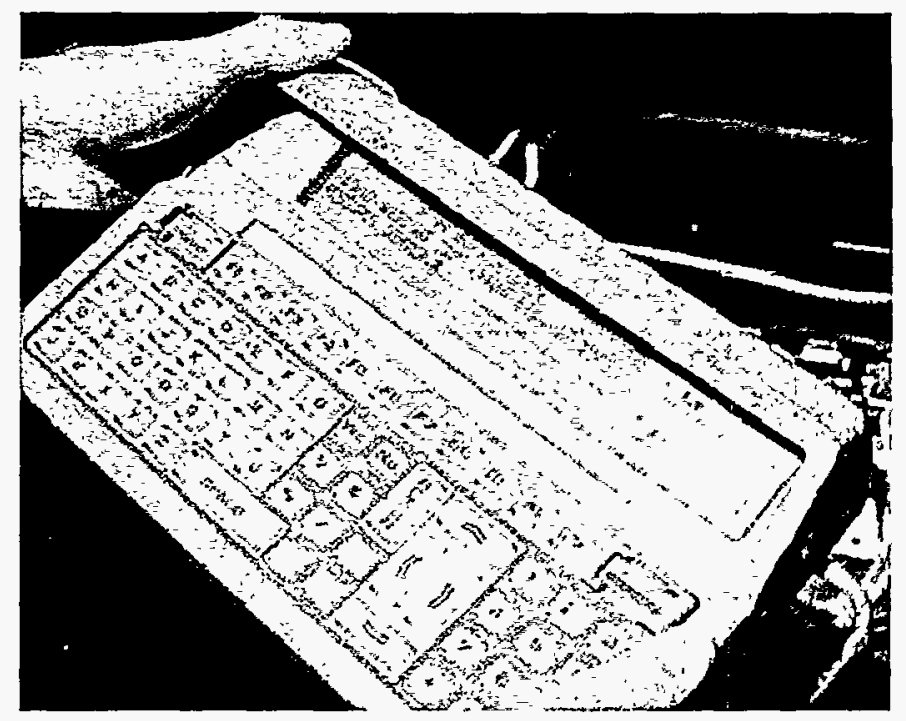

Figure 2: Mobile Data Terminal Used in NREL Van Shuttle Demo

The basic idea of TOD is to provide transportation for people from where they are to where they want to go at a time that is convenient for them. It can be thought of as a hybrid between a standard bus and a taxi-cab. Standard buses operate on a fixed-route with a fixed-schedule, tend to be relatively inexpensive, but normally don't pick you up or drop you off at the exact places you want them to. As a result, people usually choose to take their own car, and the buses are underutilized and are not as effective at achieving their purpose of VMT reduction.

The other extreme is a taxi-cab that takes a single person from their current location to their desired destination. From a transportation system efficiency viewpoint, taxi-cabs are not very effective because there are not multiple pick-ups and drop-offs during a trip to increase the number of people in the vehicle. Taxis also typically have significant "dead-head" time where they are driving without any passengers or are idling and waiting for a passenger. Hence, taxis have higher cost and lower system efficiency than is expected from TOD.

Transit-On-Demand overcomes many of the shortcomings of buses and taxis by using state-of-the-art technology in communications and global positioning systems to arrange pick-ups and drop-offs from the desired locations. Desktop computers or workstations are used to simultaneously optimize the vehicle's route to maximize the number of people being carried and minimize the delays for any given passenger. TOD supports the idea of transportation system efficiency by increasing the number of multiple-passenger trips and 
decreasing the "dead-head" time, both of which result in a reduction of VMTs.

\section{Integration With Existing Transit Systems:}

Another application of TOD that holds significant promise, but has not yet been demonstrated, is the integration of door-to-door service by TOD to drop people off at major public transportation nodes. These vehicles that are smaller than buses, primarily passenger vans, are able to penetrate neighborhoods in suburbs and other areas that are not easily serviced by conventional buses (due to vehicle weight or noise restrictions on the roads, or low bús ridership). Vehicles such as these are often called circulator or feeder vehicles because they circulate throughout the neighborhoods and feed people into the more centralized mass transit system. The concept of simple circulator vehicles has been tried in the past, but has had problems in getting a large enough ridership. Discussions with transit authorities indicate that if the concepts of TOD are implemented in circulators, particularly that of pre-scheduled or on-demand door-to-door service, that ridership might be high enough to make the system work effectively, resulting in reduced VMTs.

\section{NREL Shuttle Project Demonstrates Major Concepts of TOD}

There are some differences between the NREL shuttle demonstration and the more pure concepts of TOD which should be noted. The NREL shuttle project does have the main ingredients of vehicle location through GPS, two-way vehicle communication with a central computer server, and vehicle and route optimization for demand-responsive shuttle service. One aspect that the NREL shuttle demonstration doesn't have is a large area of coverage with complicated street networks; the region covered is three leased buildings in two separate regions of an office park and many buildings on NREL's permanent site on the opposite side of Interstate-70.

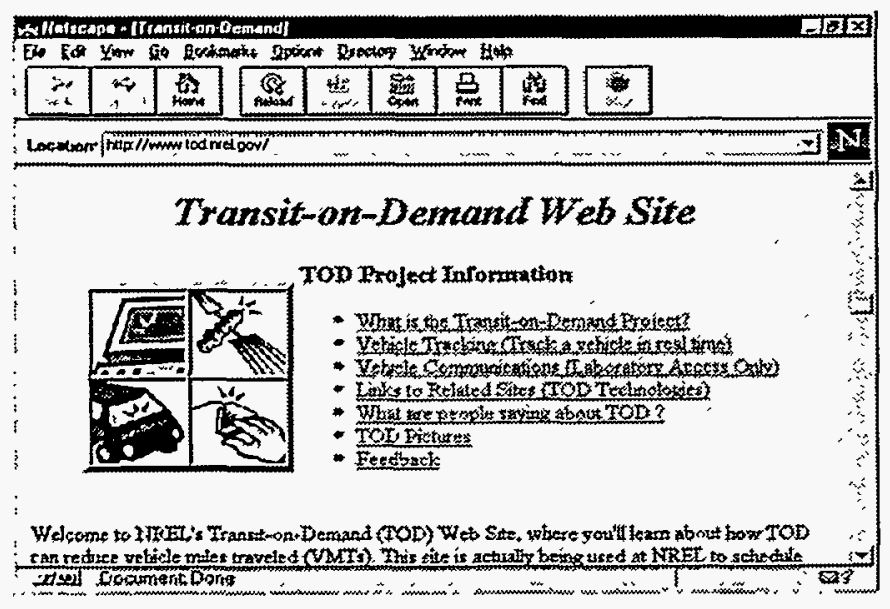

Figure 3: Screen-Capture of TOD Web Site
The other feature that the NREL shuttle demonstration doesn't have is a large number of vehicles in the fleet. The plan was to have two vehicles in the fleet, although only one has been instrumented to date. The vehicle with TOD hardware installed on it provides shuttle service for the staff, and the second vehicle is the copy-center van which makes multiple trips around the research site and the copy-center would like to have communication with the driver of that van. This limited map area and small number of vehicles has simplified the most complicated aspect of TOD, which is the routing and scheduling of passenger pickups and dropoffs.

An important convenience feature of the NREL shuttle demonstration that is not necessary for TOD to work successfully, is the internet web site that handles two-way vehicle communications, vehicle location mapping, and pickup requests (this will discussed in the section on Java $\left.{ }^{\top M}\right)$. Figure 3 shows a screen capture of the TOD home page. Since the internet was already being used for digital communication with the vehicles, and since all NREL staff have access to the web, it made sense to put the entire system on the web and have it handle everything automatically. For other situations where these two conditions are not in place, a standalone system that's not connected to the internet might be acceptable. The next demonstration of TOD by the NREL team with the Seniors' Resource Center may be a case where there is not a significant benefit of having everything on the web since not all elderly or handicapped people may have access to the web.

\section{Innovative Web Developments for Demo}

For the NREL TOD demonstration, the world wide web was used the basis for all of the system development. Netscape ver. 2.0 was used as the web browser chosen because it is the standard browser at NREL for web communications. Figure 4 shows a schematic of the initial NREL shuttle communication and web site developed, in the early stages of development before the routing with Arc/Info was implemented.

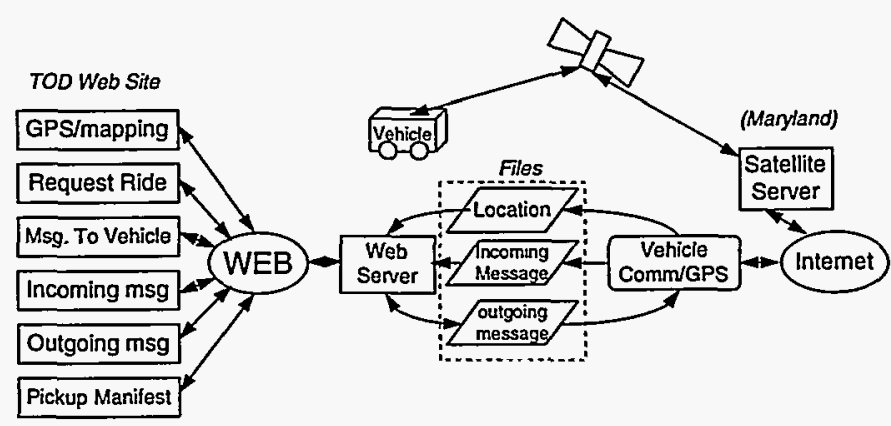

Figure 4: Schematic of Initial NREL Shuttle Communication System and Web Site

The six boxes in the left portion of Figure 4 are all functions that are activated from the main menu of the web site. The web and the web server handle all communications with the clients. The figure also shows how the communication with the vehicle is through a satellite that has a satellite server in Maryland owned by 
Mobile Datacomm, which charges a monthly fee for unlimited communication with the vehicle. The NREL vehicle communications program talks with the vehicle over the internet to get the vehicle position, writes the position to a location file, and sends and receives messages to and from the vehicle. The initial development version of the program used for testing had a ride request form which would allow the client to schedule a ride in advance or as soon as possible. Before the Arc/lnfo routing was implemented, these requests would go into a chronological queue that the driver could see, but there was no routing or schedule conflict resolution built in to the system. Figure 5 shows a schematic of the final proof-of-concept system, which uses the workstation based geographic information system (GIS) program called Arc/Info to handle all ride requests and the scheduling of pickups and dropoffs for the vehicle.

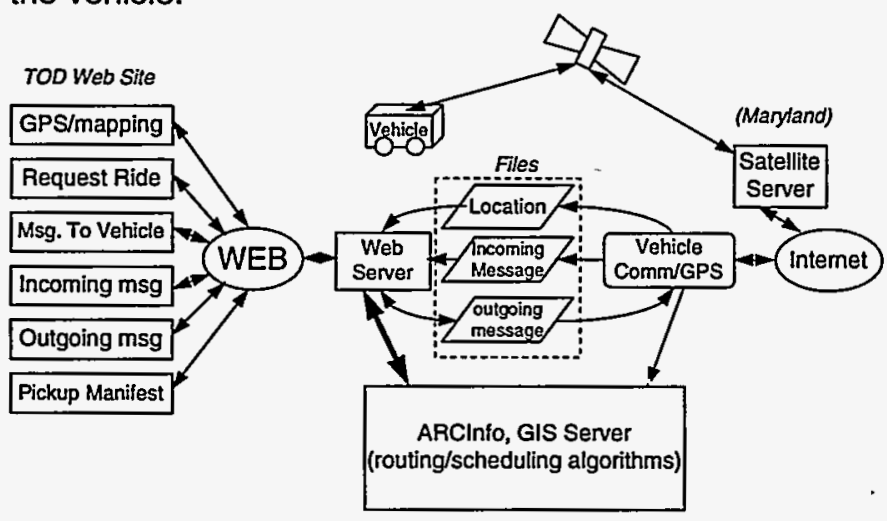

Figure 5: Schematic of NREL Shuttle Communication System and Web Site, Including Automatic Routing/Dispatching of Vehicles

The Arc/Info program has a vector based map of the streets in the vicinity of the NREL site, and uses assumed traffic "resistances" at stop-signs, turns, etc. to predict travel times. These are used in the routing and scheduling algorithms to prevent conflicts and ensure that the van is able to arrive on time for all of its pickups.

\section{Unique Java Mapping Developed:}

Netscape ver. 2.0 has a useful standard feature built-in to the browser which is the ability to execute Java $^{T M}$ "applets" (small applications) over the internet. $\mathrm{Java}^{\mathrm{TM}}$ is an internet programming language by Sun Microsystems which is similar to $C$ in structure. What this means is that a person whose computer is Java $^{\mathrm{TM}}$-capable can be using any style of computer and run an application received from an internet site.

A Java ${ }^{T M}$ applet was written for the NREL TOD site that allows the client's computer to see "live" updates of vehicle position on a map (live in this case means every 20 seconds). The goal was to provide the client a map of the area of interest with an icon of the vehicle in its current position. Since maps are very graphic intensive, sending maps frequently to multiple clients could quickly saturate the internet bandwidth out of the host site. To eliminate this problem, a Java ${ }^{\mathrm{TM}}$ program was written that transmits the map only once at the beginning of its execution, and then has the client computer request update coordinates every 20 seconds so that it can plot the current vehicle position itself on the map. This effectively minimizes the bandwidth requirement for this activity by only passing two numbers, latitude and longitude, on a periodic basis. This function is represented by the GPS/mapping box on the left side of Figure 5.

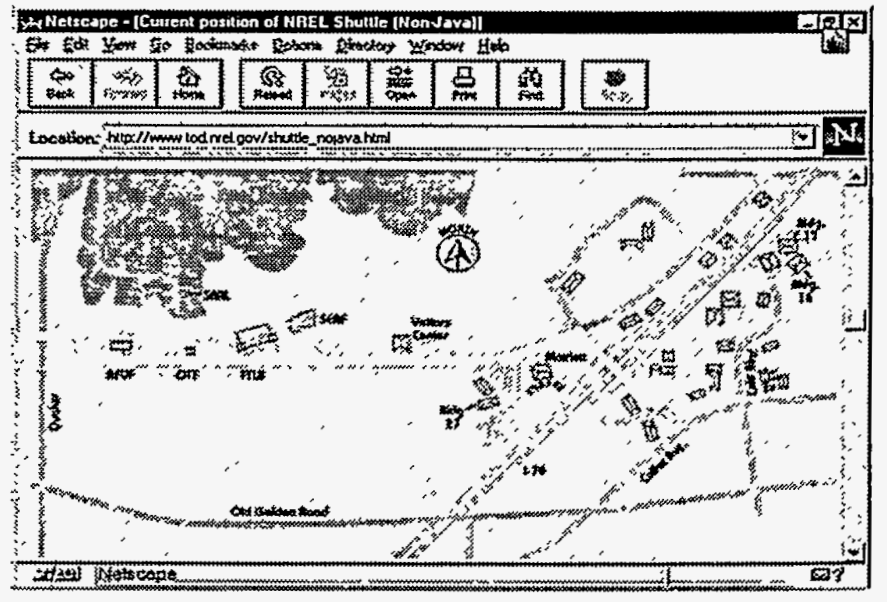

Figure 6: Screen-Capture of Mapping on Web Site

Besides the Java ${ }^{\mathrm{TM}}$ program, all of the common gateway interfaces (CGIs) were written in PERL, which is the most common language for web applications. It allows quick-development and troubleshooting because it is an interpreted language, not a compiled one.

\section{Hardware Used in Demonstration}

The two-way communication between the vehicle and the computer server was handled by a Hughes-Kenwood transmitter and receiver (model 2102 and 2202, respectively). The GPS vehicle location was obtained through a Trimble GPS antenna and card located in the transmitter.

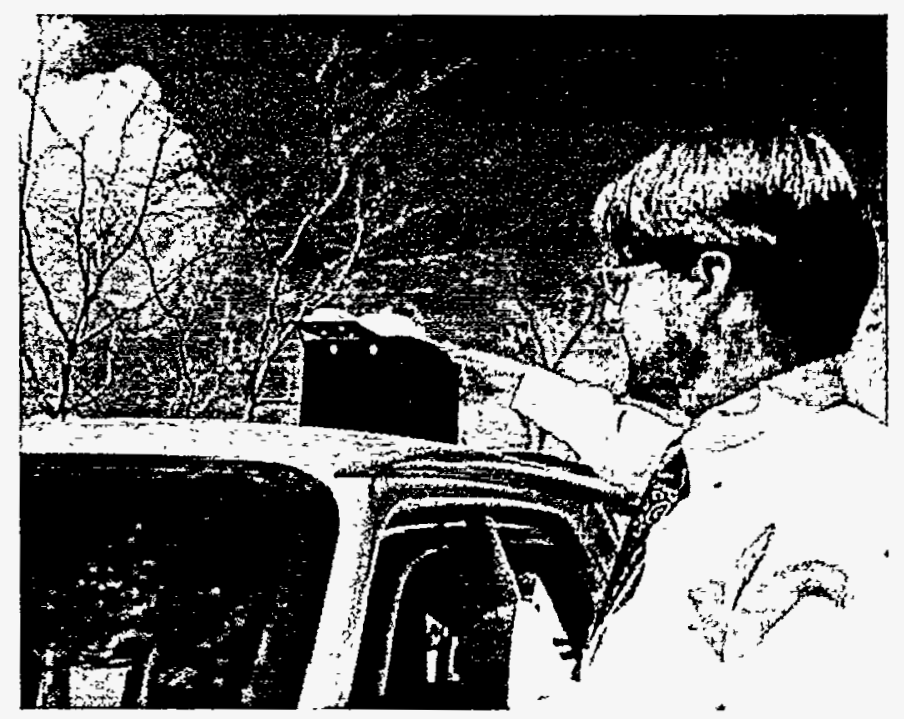

Figure 7: Author Installs Antenna for GPS and Satellite Communications During a Demonstration 
The system used also includes a mobile data terminal (MDT), which is shown in Figure 2. Figure 7 shows the author doing a temporary installation of the satellite and GPS antennas for a marketing demonstration. During these demonstrations, a car battery was used to power the system for quick setup and teardown. Figure 8 provides a close-up view of the two antennas required to allow two-way communication with the satellite server and to obtain GPS coordinates of the vehicle. Note that the cube-shaped mounting bracket was created merely for transportability between multiple test vehicles, and a final installation would have a lower profile and a more aerodynamic shape.

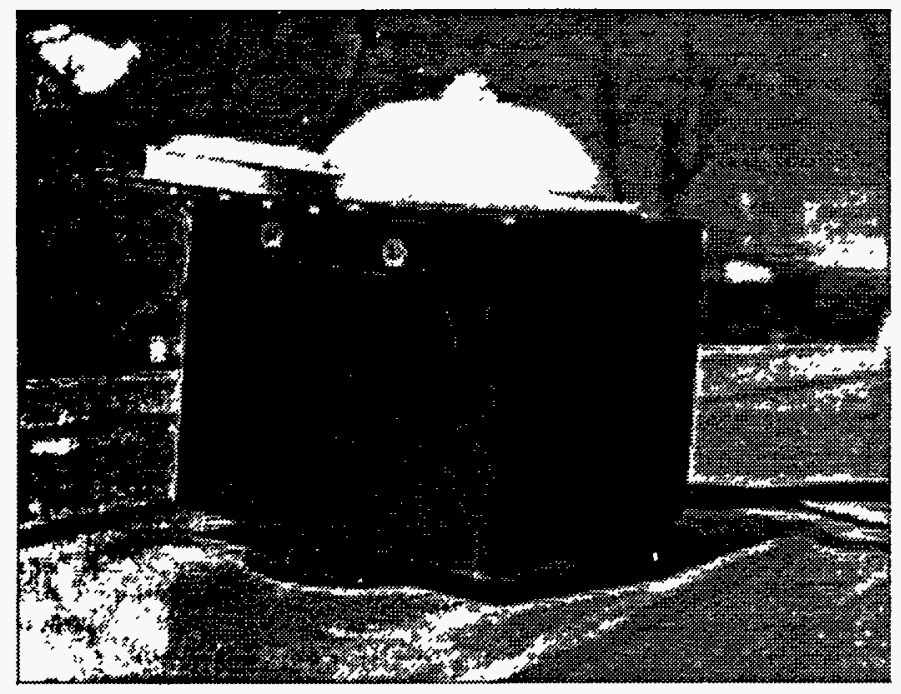

Figure 8: Close-up View of the Antennas for Two-Way Communication (large dome) and for GPS (small disc)

During the course of the NREL shuttle demonstration, some difficulties with the hardware were encountered that required sending the hardware back to American Technologies Incorporated (ATI) for repair or replacement. Some of the hardware failures may be attributed to the hardware being refurbished rather than brand new, but there were other challenges with the hardware that were reflective of TOD pushing the limits of this hardware. The hardware is normally sold to the long-haul trucking industry to enable trucks to leave with a partial load and later receive instructions for other load pickups while on the road. As a result, there had been very few real-time demands placed on the hardware; rather, it had been used as a two-way messaging system with periodic position queries. TOD increased the position queries to every 20 seconds and also required a much faster response time to messages to enable real-time routing and scheduling. Most of these issues have been resolved, but one is to increase the self-broadcast rate of position rather than using external (server-based) triggering of this position announcement.

\section{Two-Way Communications Options}

As discussed in the preceding section, the hardware used satellite communication to allow the shuttle vans and the computer server to talk with each other. There are at least two other types of communication possible that are being investigated for future TOD projects, including cellular and FM radio.

Advantages of cellular are that the cost will continue to drop as there is increased competition from new companies entering the market and that there is exciting new digital cellular communication becoming available in many cities that makes it very easy to communicate over the internet. One such digital cellular service is called the Cellular Digital Packet Data (CDPD) network. The NREL TOD team has been experimenting with a 486 laptop-based system that uses a CDPD modem and a GPS plug-in card. The external modem is a Sierra Wireless MP200 and the GPS PCMCIA card is a Trimble Mobile GPS PC Card 110.

The reason why the TOD team at NREL is experimenting with other communications options is because the Denver metro area includes tall buildings in downtown (where satellites are often blocked but there is good cellular coverage) and mountain areas (where there may be no digital cellular coverage but there is a clear view of the sky for satellite communication). It is desirable to obtain a hardware system for future projects that provides good two-way communication in the particular regions of interest.

\section{Next Steps}

In late September of 1996, the TOD team at NREL will begin working on implementing TOD for the Seniors Resource Center (SRC), a non-profit located in Jefferson County, Colorado. The SRC operates 17 shuttle vans every day to shuttle senior citizens and handicapped people from their house to doctor's appointments. shopping, etc., and then return them home. The SRC shuttle fleet will provide a good opportunity to test out the concepts of TOD on a larger scale as the fleet provided approximately 61,000 rides in 1995, driving over 290000 miles in both the urban and rural mountain areas

In addition to the Seniors Resource Center Prnect: there are also many other opportunities to implemen: TOD concepts, including potential transit circulators as discussed earlier and integrated shuttles for non shopping malls as they are opened.

\section{Conclusions}

A demonstration project at the National Renewable Energy Laboratory has shown that the TOD concept of on-demand transportation is possible with today's hardware and custom software development for a particular application. The demonstration project at NREL used the world wide web as the foundation upon which the entire communication system was built. This allowed an innovative computer program written in the Java $^{\mathrm{TM}}$ programming language to efficiently display the current position of the vehicles on a map. A non-Java ${ }^{\text {TM }}$ version was also created to allow anybody with a web browser to see the approximate location of the vans. A description of the hardware used in the demonstration project was provided, and difficulties encountered with this hardware and challenges in using it in a new 
application were discussed. Two-way communications options other than satellite were presented that may be useful in obtaining more complete coverage in mixed terrain areas, and next steps for the TOD team at NREL were outlined. Finally, the NREL demonstration shows that a fixed-route, fixed-schedule shuttle can be converted to be demand-responsive.

\section{Acknowledgments}

The author wishes to acknowledge the efforts of Bill Yerkes, who came up with the original proposal for the TOD concept, and Jim VanderWall, who took the initial concepts from Bill Yerkes and helped mold them into the ideas for the NREL demonstration project. Thanks are also due to NREL's director, Charlie Gay, who helped the project get started by providing initial seed funding, and to Christine Ervin, who supported the second phase of the project with the Seniors' Resource Center. 